\section{QUALITY OF ALUMINIUM} ALLOY SURFACE AFTER

\section{WEDM}

KATERINA MOURALOVA, JIRI KOVAR, LENKA KLAKURKOVA, MILAN KALIVODA

Brno University of Technology, Faculty of Mechanical Engineering,

Brno, Czech Republic DOI: 10.17973/MMSJ.2017_02_2016106

e-mail: mouralova@fme.vutbr.cz

Efficient machining using wire electrical discharge machining (WEDM) technology is a compromise between cutting speed and resulting surface quality. Typical morphology of the surface machined by WEDM shows a plenty of craters caused by electrospark discharges produced during the cutting process. This work is focused on assessing the impact of machine setting parameters on quantitative and qualitative evaluation of the workpiece surface of aluminium alloy AlZn6Mg2Cu. Using metallography, the surface effects arisen during the process of wire spark erosion on cross-sections of preparations were studied. Using local spot EDX microanalysis, the chemical composition of the surfaces of the samples was studied. The attention was also paid to the highest height of profile of the craters, which were studied using 3D filtered images.

KEYWORDS

WEDM, electrical discharge machining, impact layer, aluminium alloy, quality of surface

\section{INTRODUCTION}

Wire electrical discharge machining (WEDM) is a nonconventional machining technology, which uses physical principles to separate materials. The schematic view of wire electrical discharge machining process is shown in Fig. 1. The nature of EDM is based on electric discharge that occurs when putting a tool (wire electrodes) closer to a workpiece. The discharge causes melting of microscopic particles of material which are subsequently flushed from the discharge place by dielectric. In this way, craters are formed on the surface of the machined material and wire electrode [Ho 2004], [Abbas 2007].

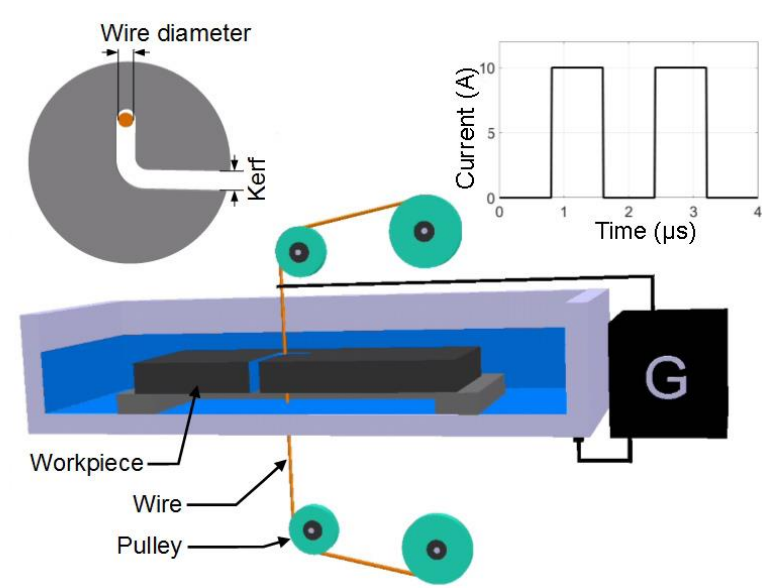

Figure 1. Schematic view of wire electrical discharge machining Process

The WEDM technology is used mainly for machining of parts that are complex in shape and indented and also with parts that are difficult to machine by conventional methods. When machining, no mechanical stresses affect the material and the only requirement is a minimum electrical conductivity of the workpiece [Kumar 2012]. It is possible to cut the materials that are extremely hard, tough or, conversely, soft, even after the final heat treatment. WEDM is a crucial technological operation in many industries, especially in the automotive, aerospace and army industry and in the manufacture of medical instruments. Due to the wide use of this machining process, the demands on the performance characteristics are constantly growing. These are mainly dimensional accuracy, speed of material removal and chemical and morphological quality of the machined surface. These characteristics are dependent on the type of the applied wire electrode, dielectric fluid, machine condition and in particular on the choice of parameters of the eroding process. These parameters can be found by various methods [Matousek 2009], [Matousek 2010], [Blecha 2011], [Blecha 2011].

[Selvakumar 2014] observed that ANOVA revealed that the cutting speed of $5083 \mathrm{Al}$ alloy was independent on wire tension and Ra was independent on pulse-off time and wire tension. An optimum parameter combination for the minimum Ra and the maximum cutting speed was obtained by the analysis of signalto- noise (S/N) ratio. [Manna 2006] optimized the CNC wire cut electrical discharge machining parameters in machining of aluminum-reinforced silicon carbide metal matrix composites using the Taguchi and Gauss elimination dual response approach method. [Lin 2002] reported the effect of current polarity, voltage, and spark on-time on EDM process by using Taguchi method.

\section{EXPERIMENTAL SETUP AND WORK-MATERIAL}

The samples for the experiment were made of wrought aluminum alloy CSN 424222 AlZn6Mg2Cu with the chemical composition as shown in Tab. 1. This material is intended for highly stressed structures in long-term working at the temperature up to $100-120{ }^{\circ} \mathrm{C}$, e.g. for aircraft production (covers, longitudinal ribs, reinforcements, bulkheads). The material has a high ultimate strength $\mathrm{Rm}$ from 190 to $590 \mathrm{MPa}$ and hardness from 60 to $180 \mathrm{HV}$ depending on the kind of the metallurgical semi product and its heat treatment. The thickness of the machined material was $53 \mathrm{~mm}$.

\begin{tabular}{|c|c|c|c|c|c|c|c|}
\hline Contents & $\mathrm{Zn}$ & $\mathrm{Cr}$ & $\mathrm{Mg}$ & $\mathrm{Mn}$ & $\mathrm{Cu}$ & $\mathrm{Fe}$ & $\mathrm{Si}$ \\
\hline $\begin{array}{c}\text { Min } \\
\text { (wt\%) }\end{array}$ & 5.0 & 0.1 & 1.8 & 0.2 & 1.4 & & \\
\hline $\begin{array}{c}\text { Max } \\
\text { (wt\%) }\end{array}$ & 7.0 & 0.25 & 2.8 & 0.6 & 2.0 & 0.5 & 0.5 \\
\hline
\end{tabular}

Table 1. Chemical composition of aluminium alloy AlZn6Mg2Cu set by a standard

EDM wire cutting machine EU64 from MAKINO was used for the production of samples. The PENTA CUT E brass wire with diameter size of $0.25 \mathrm{~mm}$ made by company Penta Trading inc. was used as a tool electrode. The chemical composition of the wire was $60 \%$ copper and $40 \%$ zinc. The workpiece was immersed in the deionized water with high pressure waterjets flushing to remove debris in the gap between the wire electrode and workpiece.

The machining parameters selection was performed in the course of preliminary tests. There were used different settings of gap voltage, pulse on time $\left(T_{\text {on }}\right)$, pulse off time $\left(T_{\text {off }}\right)$, wire feed and discharge current as shown in Tab. 2. 


\begin{tabular}{|c|c|c|c|c|c|c|}
\hline 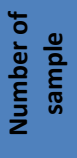 & 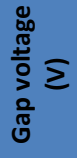 & 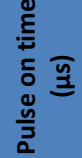 & 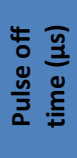 & 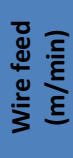 & 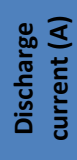 & 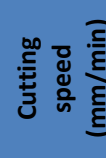 \\
\hline 1 & 50 & 6 & 50 & 10 & 25 & 1.55 \\
\hline 2 & 50 & 6 & 40 & 12 & 30 & 1.95 \\
\hline 3 & 50 & 6 & 30 & 14 & 35 & 2.5 \\
\hline 4 & 50 & 8 & 50 & 12 & 35 & 2 \\
\hline 5 & 50 & 8 & 40 & 14 & 30 & 2 \\
\hline 6 & 50 & 8 & 30 & 10 & 25 & 2.25 \\
\hline
\end{tabular}

Table 2. Machining parameters used in the experiments

\section{EVALUATION OF THE MACHINED SURFACE}

The machined surfaces of the samples and wires used for cutting were cleaned in the ultrasonic cleaning and studied using scanning electron microscope (SEM) LYRA3 from Tescan. This device was equipped with an energy-dispersive $x$-ray detector (EDX) allowing the study of changes in the chemical composition of the surface due to WEDM. For the analysis of the machined material interface by the WEDM method, the metallographic cuts of cross sections were prepared. These preparations were prepared by conventional techniques - wet grinding and polishing with diamond pastes using automatic preparation system TEGRAMIN 30 from Struers. Final mechanical chemical polishing was performed using OP-Chem suspension from Struers. After etching by the Fuss etchant, the structure of the material was observed by light and electron microscopy on the 3D opto-digital microscope with high resolution OLYMPUS DSX 510 and on SEM.

\subsection{Analysis of the morphology of the sample surface}

The surface and the chemical composition on the surface of the samples were observed using electron and optical microscopy. The surface morphology consists of a plenty of craters caused by various electrical discharges. These craters were observed shallow, as in Fig. 2, or deep, which are in Fig. 3.

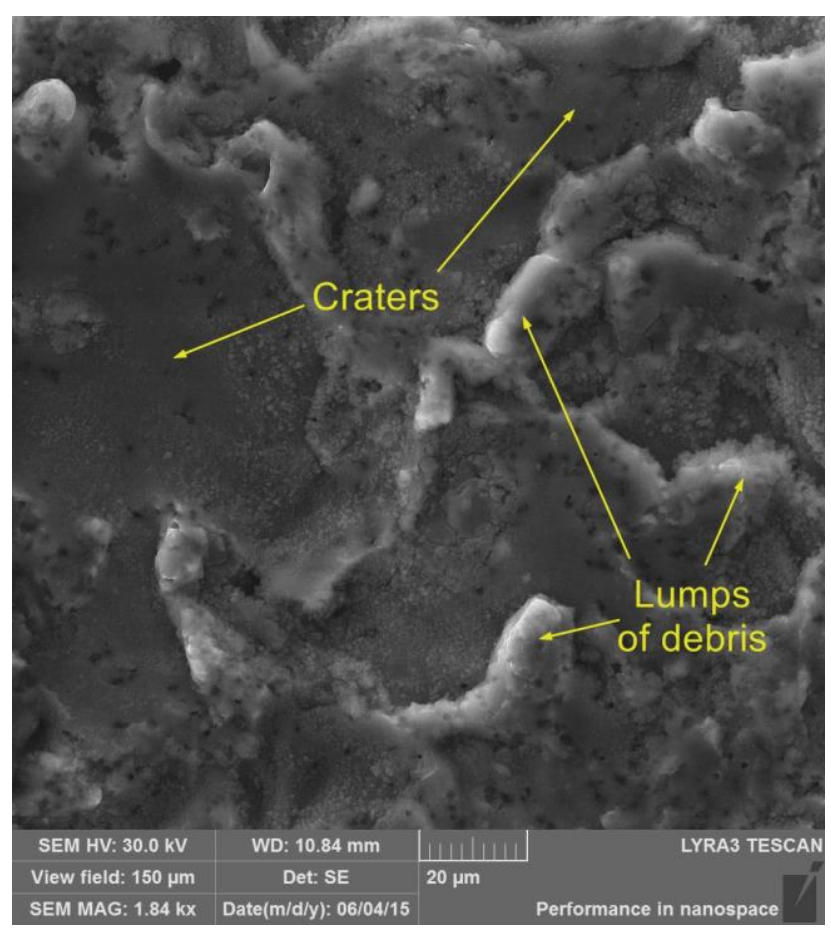

Figure 2. SEM picture of sample $n r .5, T_{\text {on }}=8 \mu \mathrm{s}, \mathrm{T}_{\text {off }}=40 \mu \mathrm{s}$, wire feed $=14$ $\mathrm{m} / \mathrm{min}$, current $=30 \mathrm{~A}$
$20 \%$ of the surface of all samples is covered with lumps of debris as shown in Fig. 2.

Surface microcracks were detected in approximately $5 \%$ of the surface of the examined samples, see Fig. 3. Analyzed surface morphology shows signs that are typical for the material which was completely melted and in which consequently there was a rapid cooling. The surface is formed by dendritic areas with a smooth surface with a low frequency of fine surface microcracks and cracks resulting from volume changes caused by phase transformations due to the diffusion of the two materials (the material being cut and the material of the cutting wire), and mainly as a result of the expansion process caused by the high speed cooling (enormously fast conversion of the melt into the solid solution).

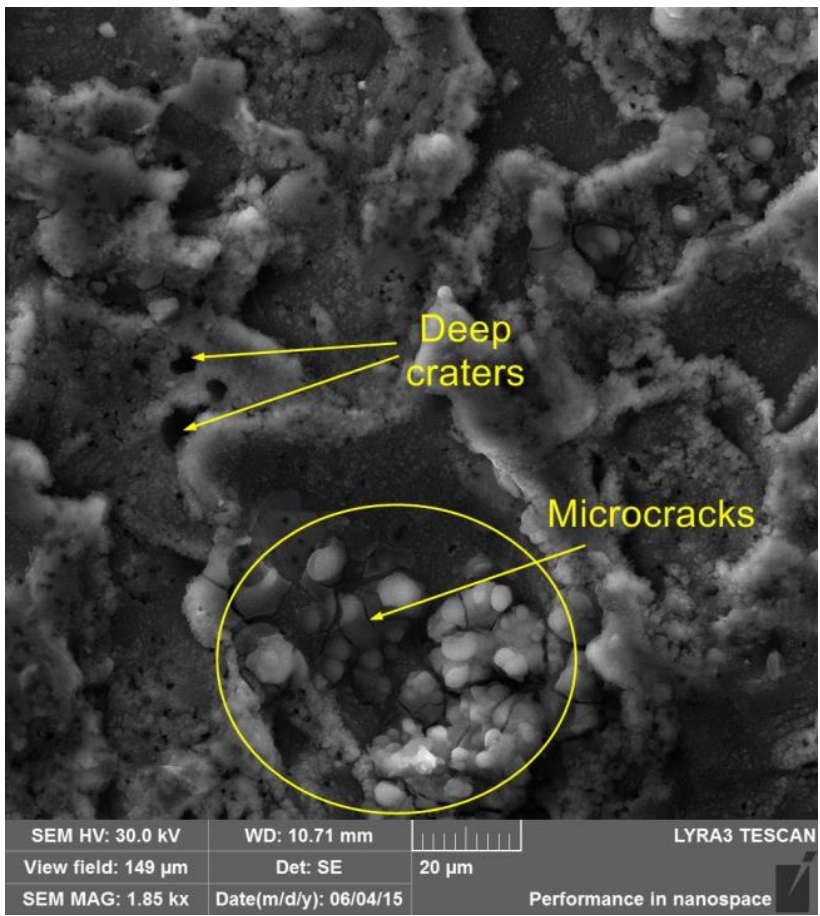

Figure 3. SEM picture of sample $\mathrm{nr}$. 3, $\mathrm{T}_{\mathrm{on}}=6 \mu \mathrm{s}$, $\mathrm{T}_{\text {off }}=30 \mu \mathrm{s}$, wire feed $=14$ $\mathrm{m} / \mathrm{min}$, current=35 A

All studied surfaces affected by electrospark cutting process were measured for chemical composition using local EDX of the surface microanalysis. The results of the analyses are summarized in Tab. 3.

\begin{tabular}{|c|c|c|c|c|c|c|}
\hline Sample & $\begin{array}{c}\mathrm{C} \\
\text { (wt\%) }\end{array}$ & $\begin{array}{c}\mathbf{0} \\
\text { (wt\%) }\end{array}$ & $\begin{array}{c}\mathrm{Al} \\
\text { (wt\%) }\end{array}$ & $\begin{array}{c}\mathrm{Cu} \\
\text { (wt\%) }\end{array}$ & $\begin{array}{c}\mathrm{Zn} \\
\text { (wt\%) }\end{array}$ & $\begin{array}{c}\mathrm{Mn} \\
\text { (wt\%) }\end{array}$ \\
\hline $\mathbf{1}$ & 7.6 & 29.9 & 43.2 & 2.9 & 16.4 & \\
\hline $\mathbf{2}$ & 9.5 & 28.7 & 52.6 & 1.1 & 7.1 & 1.0 \\
\hline $\mathbf{3}$ & 5.9 & 11.9 & 71.0 & 2.7 & 8.5 & \\
\hline $\mathbf{4}$ & 9.6 & 25.6 & 59.8 & 0.9 & 4.1 & 0.6 \\
\hline $\mathbf{5}$ & 9.9 & 22.5 & 56.9 & 2.0 & 7.6 & 1.1 \\
\hline $\mathbf{6}$ & 10.4 & 23.9 & 60.3 & 1.1 & 4.3 & 1.9 \\
\hline
\end{tabular}

Table 3. Measurement of chemical composition on the sample surface

The surface of the samples mainly consisted of aluminium, which is an essential element of the workpiece material. Furthermore, an amount of $\mathrm{Cu}$ and $\mathrm{Zn}$ was analyzed, which was significantly higher than their limit content in the base material. From these analyses it is clear that the surface of the sample is heavily contaminated by cutting fumes (by wire electrode).

To visualize individual craters in the space, 3D images of the surface of each sample were created. An example of these images is in Fig. 4, which shows the unfiltered surface of the sample No. 2. The total profile heights of these craters differ 
from each other. The values of the heights are put in Graph 1 and they were taken from the colour-filtered images, the example of which is shown in Fig. 5. 10 filtered images were taken on each sample at random places on the surface. From the measured values of the highest profile heights, it is evident that the height differences of the craters in individual places on the sample surface vary considerably. The biggest difference of the heights of ten measuring points was detected in the sample 3 , when the difference was almost $13 \mu \mathrm{m}$. The maximum measured profile height was $36 \mu \mathrm{m}$ and the minimum was only $22 \mu \mathrm{m}$.

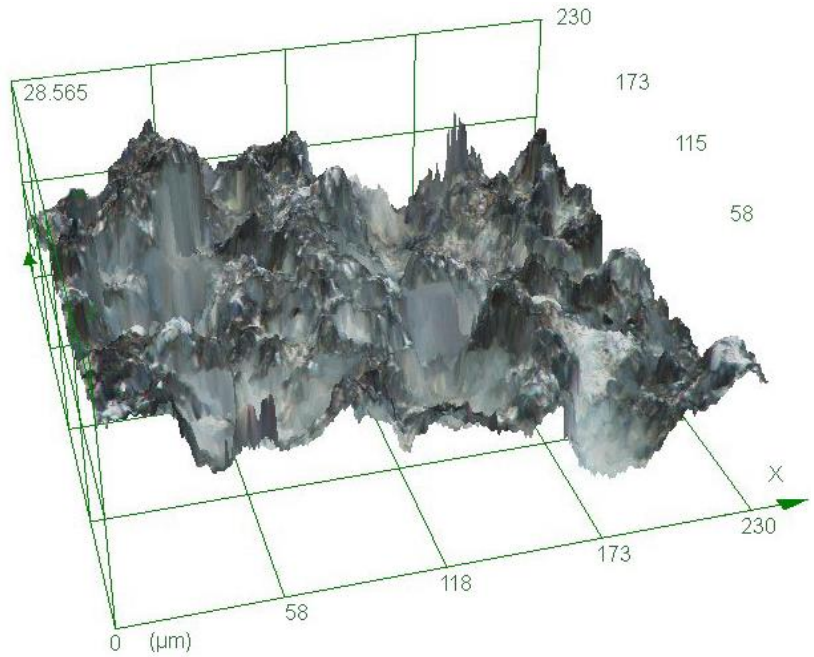

Figure 4. 3D picture of sample no. 2 magnified $1200 x, T_{\text {on }}=6 \mu$ s, $T_{\text {off }}=40$ $\mu \mathrm{s}$, wire feed $=12 \mathrm{~m} / \mathrm{min}$, current $=30 \mathrm{~A}$

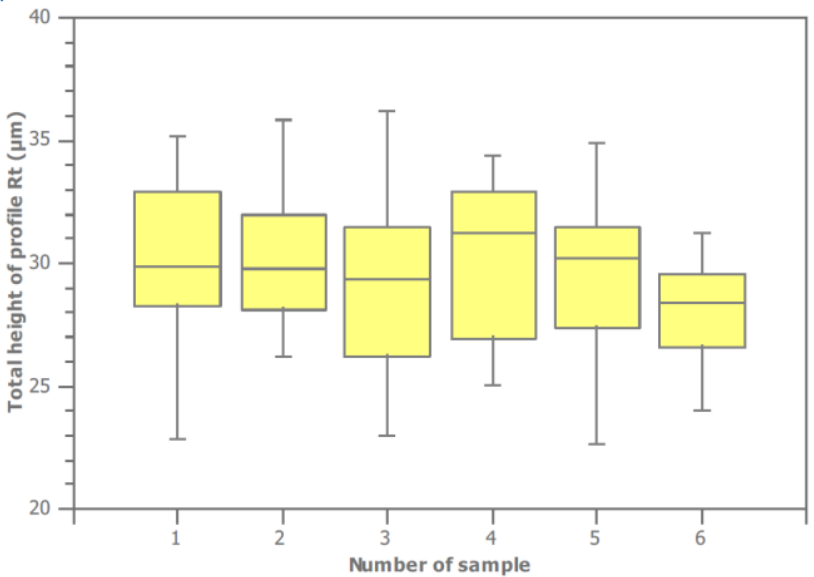

Graph 1. The highest profile height of the individual samples

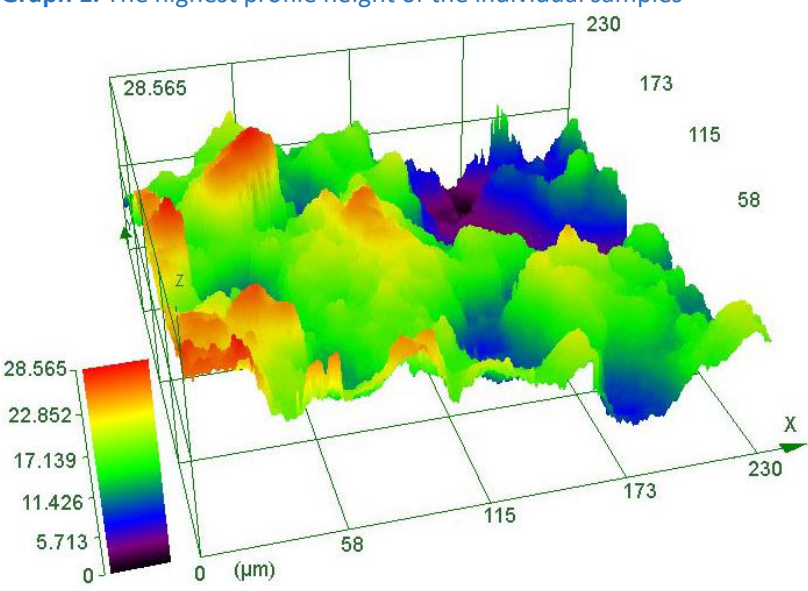

Figure 5. 3D picture of sample no. 2 magnified $1200 x, T_{\text {on }}=6 \mu$ s, $T_{\text {off }}=40$ $\mu \mathrm{s}$, wire feed $=12 \mathrm{~m} / \mathrm{min}$, current $=30 \mathrm{~A}$

\subsection{Microstructural analysis of subsurface area}

The morphology of the surface after the WEDM cutting process and simultaneously the microstructure of the affected subsurface layer of the cut material were studied in detail using metallographic preparations of the cross sections of the cut samples. The appearance of the microstructure of the material affected by the cutting process using the WEDM is documented in Fig. 6. The layer of the products from the cutting was studied using 3D opto-digital microscope with high resolution OLYMPUS DSX 510 at $24 \mathrm{fps}$. In the subsurface area, we can observe a large number of cracks parallel to the cut surface of the sample (Fig. 6) that were most likely formed due to internal stresses at very rapid cooling during the cutting process. Given the number of cracks, it can be assumed that a spontaneous delamination of the top part of the material (about 5-10 $\mu \mathrm{m}$ ) will occur and it will be strongly disturbed by longitudinal cracks around the surface of the component.

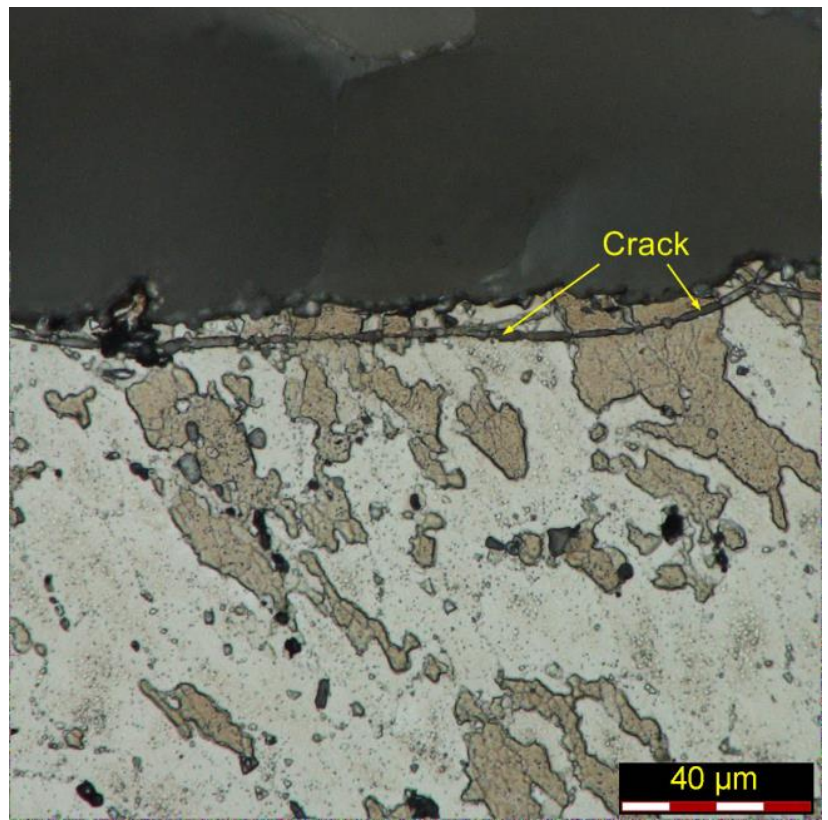

Figure 6. Cross cut microstructure after WEDM of sample no. 1 (LM), magnified $1600 \mathrm{x}, \mathrm{T}_{\text {on }}=6 \mu \mathrm{s}, \mathrm{T}_{\text {off }}=50 \mu \mathrm{s}$, wire feed $=10 \mathrm{~m} / \mathrm{min}$, current $=25 \mathrm{~A}$

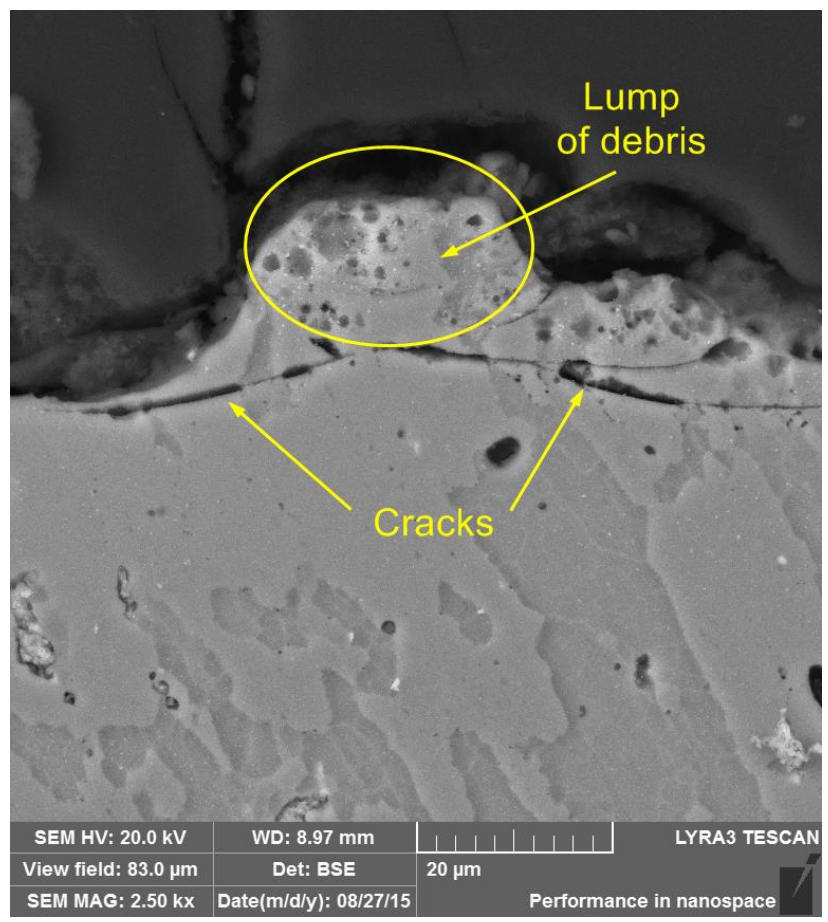

Figure 7. Cross cut microstructure after WEDM of sample nr. 1 (SEM), magnified $1600 \mathrm{x}, \mathrm{T}_{\text {on }}=6 \mu \mathrm{s}, \mathrm{T}_{\text {off }}=50 \mu \mathrm{s}$, wire feed $=10 \mathrm{~m} / \mathrm{min}$, current $=25$ A 
The cracks along the whole length (Fig. 7) in the subsurface area of all samples were also studied using electron microscopy.

\section{CONCLUSIONS AND DISCUSSION}

The surface morphology consists of a number of craters [Luo 2009], [Han 2007] and also lumps of debris that were detected at $20 \%$ of the surface of the samples. The surface microcracks formed as a result of expansion processes caused by highspeed cooling were detected at $5 \%$ of the surface of the samples. Long cracks, which are located on each examined sample over the whole length of the cut, were found in microstructural analysis of subsurface areas. These cracks would probably cause a separation of a layer of a thickness of 5 to $10 \mu \mathrm{m}$ from the surface of the workpiece in the future. The cracks on the surfaces machined by wire spark erosion also occur on pure titanium [Kumar 2013] or its alloys [Aspinawall 2008].

The analysis of the chemical composition suggests that the surface of some samples are covered with copper and zinc from a brass wire electrode, because the percentage of these elements on the surface is higher than the composition that is required by the standard for aluminium alloy AlZn $6 \mathrm{Mg} 2 \mathrm{Cu}$. The effect of clinging of the cutting wire material on the machined surface was also observed for pure titanium [Kumar 2013], [Somashekhar 2010].

The total height of profile was taken from the filtered 3D images of the surface. The maximum measured profile height is $36 \mu \mathrm{m}$ and the minimum is only $22 \mu \mathrm{m}$. The highest difference of the heights of ten measuring points was detected in the sample 3 , when the difference was almost $13 \mu \mathrm{m}$.

\section{ACKNOWLEDGEMENTS}

This work is an output of research and scientific activities of NETME Centre, supported through project NETME CENTRE PLUS (LO1202) by financial means from the Ministry of Education, Youth and Sports under the "National Sustainability Programme I“.

This research has been financially supported by the Ministry of Education, Youth and Sports of the Czech Republic under the project CEITEC 2020 (LQ1601).

This work was carried out with the support of core facilities of CEITEC - Central European Institute of Technology under CEITEC - open access project, ID number LM2011020, funded by Ministry of Education, Youth and Sports of the Czech Republic under the activity Projects of major infrastructures for research, development and innovations.

\section{REFERENCES}

[Abbas 2007] Abbas, N. M., Solomon, D. G., \& Bahari, M. F. (2007) A review on current research trends in electrical discharge machining (EDM). International Journal of machine tools and Manufacture, 47(7), pp. 1214-1228.

[Aspinwall 2008] Aspinwall, D. K., Soo, S. L., Berrisford, A. E., \& Walder, G. (2008) Workpiece surface roughness and integrity after WEDM of Ti-6Al-4V and Inconel 718 using minimum damage generator technology. CIRP Annals-Manufacturing Technology,57(1),pp.187-190.

[Blecha 2011a] Blecha, P., Blecha, R., Bradac, F. (2011) Integration of Risk Management into the Machinery Design Process. In Mechatronics Springer Berlin Heidelberg, pp. 473482.

[Blecha 2011b] Blecha, P., \& Prostrednik, D. (2011) Influence on the failure probability. Annals of DAAAM \& Proceedings, pp. 1113.

[Han 2007] Han, F., Jiang, J., \& Yu, D. (2007) Influence of discharge current on machined surfaces by thermo-analysis in finish cut of WEDM. International Journal of Machine Tools and Manufacture, 47(7), pp. 1187-1196.

[Ho 2004] Ho, K. H., Newman, S. T., Rahimifard, S., \& Allen, R. D. (2004). State of the art in wire electrical discharge machining (WEDM). International Journal of Machine Tools and Manufacture, 44(12), pp. 1247-1259.

[Kumar 2012] Kumar, R., \& Singh, S. (2012) Current Research Trends in Wire Electrical Discharge Machining: An Overview. International Journal on Emerging Technologies, 3(1), pp. 3340.

[Kumar 2013] Kumar, A., Kumar, V., \& Kumar, J. (2013) Experimental Investigation on material transfer mechanism in WEDM of pure titanium (Grade-2). Advances in Materials Science and Engineering.

[Lin 2002] Lin, J. L., \& Lin, C. L. (2002) The use of the orthogonal array with grey relational analysis to optimize the electrical discharge machining process with multiple performance characteristics. International Journal of Machine Tools and Manufacture, 42(2), pp. 237-244.

[Luo 2009] Luo, Y. F., \& Tao, J. (2009) Metal removal in EDM driven by shifting secondary discharge. Journal of Manufacturing Science and Engineering, 131(3).

[Manna 2006] Manna, A., \& Bhattacharyya, B. (2006) Taguchi and Gauss elimination method: a dual response approach for parametric optimization of CNC wire cut EDM of PRAISiCMMC. The International Journal of Advanced Manufacturing Technology, 28(1-2), pp. 67-75.

[Matousek 2009] Matousek, R., Bednar, J. (2009) Grammatical Evolution: Epsilon Tube in Symbolic Regression Task. In MENDEL 2009, Mendel Journal series. MENDEL. Brno, BUT. pp. 9 - 15. ISBN 978-80-214-3884-2, ISSN 1803-3814.

[Matousek 2010] Matousek R., Bednar J., (2010) Grammatical evolution and STE criterion: Statistical properties of STE objective function, Lecture Notes in Electrical Engineering, vol 68, pp 131-142, doi: 10.1007/978-90-481-9419-3_11.

[Selvakumar 2014] Selvakumar, G., Sornalatha, G., Sarkar, S., \& Mitra, S. (2014) Experimental investigation and multi-objective optimization of wire electrical discharge machining (WEDM) of 5083 aluminum alloy. Transactions of Nonferrous Metals Society of China, 24(2), pp. 373-379.

[Somashekhar 2010] Somashekhar, K. P., Ramachandran, N., \& Mathew, J. (2010) Material removal characteristics of microslot (kerf) geometry in $\mu$-WEDM on aluminum. The International Journal of Advanced Manufacturing Technology, 51(5-8), pp. 611-626.

\section{CONTACT}

Ing. Katerina Mouralova, Ph.D.

Brno University of Technology

Faculty of Mechanical Engineering

Technicka 2896/2, 61669 Brno, Czech Republic

e-mail:mouralova@fme.vutbr.cz 